\title{
Xantoma verruciforme vulvar: relato de caso
}

\author{
Xantoma verruciforme vulvar: case report \\ Xantoma verruciforme vulvar: relato de caso
}

Márcia Cristina Taveira Pucci Green ${ }^{1,2 *}$, Marcela Scalia ${ }^{2}$, Laura Ferreira França Pazeto², João Hercos Neto², Leonardo Vendrame Barbosa², André Luiz Meles Ferreira'.

\section{RESUMO}

Relato de caso: Paciente do sexo feminino, 76 anos, encaminhada ao Ambulatório de Ginecologia da Universidade de Franca com a queixa de lesão em pequeno lábio esquerdo, de surgimento há mais de um ano. À vulvoscopia, foi observada lesão em placa sobrelevada, verrucosa, em borda lateral de pequeno lábio esquerdo, sem demais achados clínicos. Após 7 dias, foi realizada a exérese da lesão vulvar, a qual foi enviada à análise anatomopatológica. Retornou ao ambulatório para avaliação pós-cirúrgica, assintomática, portando o laudo da análise histológica da lesão, que demonstrou se tratar de xantoma verruciforme, sem sinais de malignidade. Foi indicado seguimento ambulatorial à paciente. Discussão: Sabe-se que essas lesões afetam principalmente mulheres na pós-menopausa e geralmente se apresentam como lesão superficial única, espessa, irregular ou verrucosa e assintomática, exatamente o que foi encontrado na paciente analisada, tanto em relação ao quadro epidemiológico, quanto em relação ao quadro clinico apresentado.

Palavras-chave: Biópsia, Pseudotumor, Vulva.

\begin{abstract}
Case report: A 76-year-old female patient was referred to the Gynecology Outpatient Clinic of the University of Franca with a complaint of a lesion on the left inner lip, which appeared more than a year ago. At vulvoscopy, a raised, verrucous plaque was observed on the lateral border of the left inner lip, with no other clinical findings. After 7 days, the excision of the vulvar lesion was performed, which was sent to anatomopathological analysis. She returned to the outpatient clinic for post-surgical evaluation, asymptomatic, carrying the report of the histological analysis of the lesion, which showed that it was a verrucciform xanthoma, with no signs of malignancy. Outpatient follow-up was indicated to the patient. Discussion: It is known that these lesions affect mainly postmenopausal women and usually present as single, thick, irregular or verrucous and asymptomatic superficial lesion, exactly what was found in the analyzed patient, both in relation to the epidemiological picture and in relation to the clinical picture presented.
\end{abstract}

Keywords: Biopsy, Pseudotumor, Vulva.

\section{RESUMEN}

Relato de caso: Paciente del sexo femenino, 76 años, encaminada al Ambulatorio de Ginecología de la Universidad de Franca con la queja de lesión en pequeño labio izquierdo, de surgimiento hace más de un año. A la vulvascopia, se observó lesión en placa sobrelevada, verrucosa, en borde lateral de pequeño labio izquierdo, sin demasiados hallazgos clínicos. Después de 7 días, se realizó la exéresis de la lesión vulva, la cual fue enviada al análisis anatomopatológico. Volvió al ambulatorio para evaluación post-quirúrgica, asintomática, portando el laudo del análisis histológico de la lesión, que demostró tratarse de xantoma verruz, sin signos de malignidad. Se ha indicado un seguimiento ambulatorial a la paciente. Discusión: Se sabe que estas lesiones afectan principalmente a las mujeres en la posmenopausia y generalmente se presentan como lesión superficial única, espesa, irregular o verrucosa y asintomática, exactamente lo que fue encontrado en la paciente analizada, tanto en relación al cuadro epidemiológico, en relación al cuadro clínico presentado.

Palabras-Clave: Biópsia, Pseudotumor, Vulva.

${ }^{1}$ Fundação Santa Casa de Misericórdia de Franca, Franca-SP. *E-mail: joaohercosneto@gmail.com

2 Faculdade de Medicina da Universidade de Franca (UNIFRAN), Franca-SP. 


\section{INTRODUÇÃO}

O Xantoma Verruciforme (XV) consiste em uma lesão não tumoral reativa e o seu local de aparecimento mais comum é na cavidade bucal (AGARWAL-ANTAL N, et al, 2002; ROSA EA e AMORIM RFB, 2014). Frequentemente, essas lesões são descritas em territórios extra-orais como no ânus, membros superiores e inferiores, região sacral, nariz, pênis, escroto e vulva. Neste último caso, em particular, são classificados como Xantomas Vegas, do inglês verruciform genital associated (STIFF KM e COHEN PR, 2017; ARIAS VL et al. 2010).

Tal lesão, semelhante a uma verruga, foi descrita primariamente em 1903 por Sachs, e na década de 1980 Shafer já havia descrito casos do XV. Com o avançar dos estudos no século XXI, já era conhecido que essa lesão tinha uma pequena predileção pelo sexo masculino abaixo dos 50 anos, numa relação homem-mulher de 1,6:1,0, e, acima desta idade, dava-se preferência ao sexo feminino, numa relação mulher-homem de 1,0:0,8. Deste total, três quartos situavam-se em região de mucosa mastigatória. Trata-se de uma doença rara de etiopatogenia não muito bem esclarecida, possuindo aparência verrucosa, por vezes papilomatosa, séssil ou polipoide (STIFF KM e COHEN PR, 2017; BEUTLER BD e COHEN PR, 2015; MONTEIRO MCL et al., 2016).

Presume-se que para ocorrê-la, é necessário inicialmente uma agressão aos ceratócitos, os quais produzem fatores que levarão à resposta inflamatória, com consequente proliferação celular benigna, recrutamento de neutrófilos, que acabam aumentando a degradação dos ceratócitos e liberação de substâncias que promovem reparação ao tecido lesado. Logo, acredita-se que o comportamento reparativo crônico seja base da formação da lesão (ARIAS VL et al., 2010; MEZQUITA G et al., 2018).

Muito se pensou que, devido aparência semelhante, tal lesão podia estar associada ao papilomavírus humano (HPV), porém não há comprovação da presença deste vírus em XV pela reação em cadeia da polimerase (PCR). Características histológicas que falam a favor do xantoma englobam a epiderme acantótica com paraqueratose, a qual se prolonga ao fundo do epitélio, as cristas retas e alongadas uniformemente e a infiltração neutrofílica na derme com os histiócitos espumosos (STIFF KM e COHEN PR, 2017).

Sabe-se que o XV pode estar relacionado a outras doenças como nevo epidérmico, lúpus eritematoso sistêmico (LES), pênfigo vulgar, epidemólise bolhosa e carcinoma de células escamosas (ARIAS VL, et al., 2010; MANNES KD, et al., 1999).

Em seu aspecto clínico, os XV se assemelham ao condiloma acuminado, a papulose bowenóide, a eritroplasia de Queyrat, molusco contagioso gigante, ceratose seborreica, carcinoma espinocelular (CEC), verruga vulgar e neoplasia intraepitelial vulvar, que fazem parte de uma gama de diagnósticos diferenciais que devem ser discriminados pela histopatologia. $O$ tratamento tipicamente se dá pela exérese cirúrgica simples (STIFF KM e COHEN PR, 2017).

Neste artigo será apresentado o relato de um caso de uma paciente do sexo feminino de 76 anos com o diagnóstico de XV vulvar, descrevendo seu diagnóstico, tratamento e evolução clínica.

\section{DETALHAMENTO DO CASO}

Paciente do sexo feminino, 76 anos, encaminhada ao Ambulatório de Ginecologia da Universidade de Franca com a queixa de lesão em pequeno lábio esquerdo, de surgimento há mais de um ano, associada a leucorreia esbranquiçada grumosa de odor fétido e prurido vulvar. Em sua história patológica prévia, constava hipertensão arterial sistêmica, doença de Parkinson, câncer de pele não especificado há mais de 26 anos, carcinoma células escamosas tipo basalóide em base nasal há 3 anos e Doença de Bowen em braço esquerdo há 1 ano do atendimento. Com relação aos antecedentes ginecológicos, possuía história de 2 partos cesarianos e 1 aborto prévio. Referiu, ainda, vida sexual inativa no momento da consulta e seu último exame de citologia oncótica há 2 anos. Realizava uso contínuo de ácido acetilsalicílico (AAS), pramipexol, hidroclorotiazida e Ginkgo biloba. Ao exame físico, apresentava-se em bom estado geral, afebril, hidratada e normocorada. À vulvoscopia, foi observada lesão em placa sobrelevada, verrucosa, em borda lateral de 
pequeno lábio esquerdo, sem demais achados clínicos. O teste com azul de toluidina foi positivo (Figura 1A), assim como o teste aceto branco. À colposcopia, notou-se prolapso de mucosa de parede anterior grau 2, colo atrófico com orifício puntiforme, presença de petéquias traumáticas e secreção esbranquiçada próximo ao orifício do colo.

Figura 1 - Aspecto da lesão em pequeno lábio esquerdo com teste com azul de toluidina positivo (A). Pequeno lábio esquerdo em cicatrização no $20^{\circ}$ dia após excisão da lesão (B). Aspecto da vulva após excisão da lesão (C).

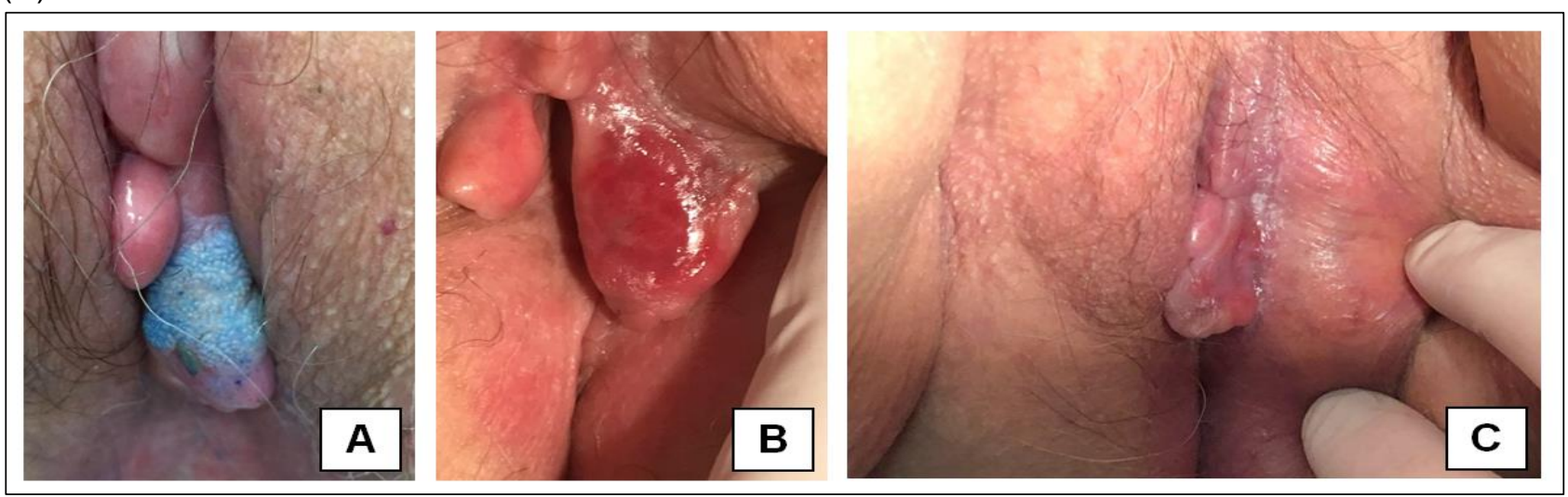

Fonte: Autores, 2018.

A junção escamo-colunar (JEC) não foi visualizada e não havia evidências de alterações vasculares. Levantada a hipótese diagnóstica de carcinoma de vulva e candidíase, foi colhida amostra para exame de citologia oncótica, realizada biópsia da lesão e encaminhamento da paciente à vulvectomia simples e indicado tratamento clínico da vulvovaginite (Figura 2 A e B).

Figura 2 - Histologia da arquitetura verrucosa (A) e das células xantomatosas (B).

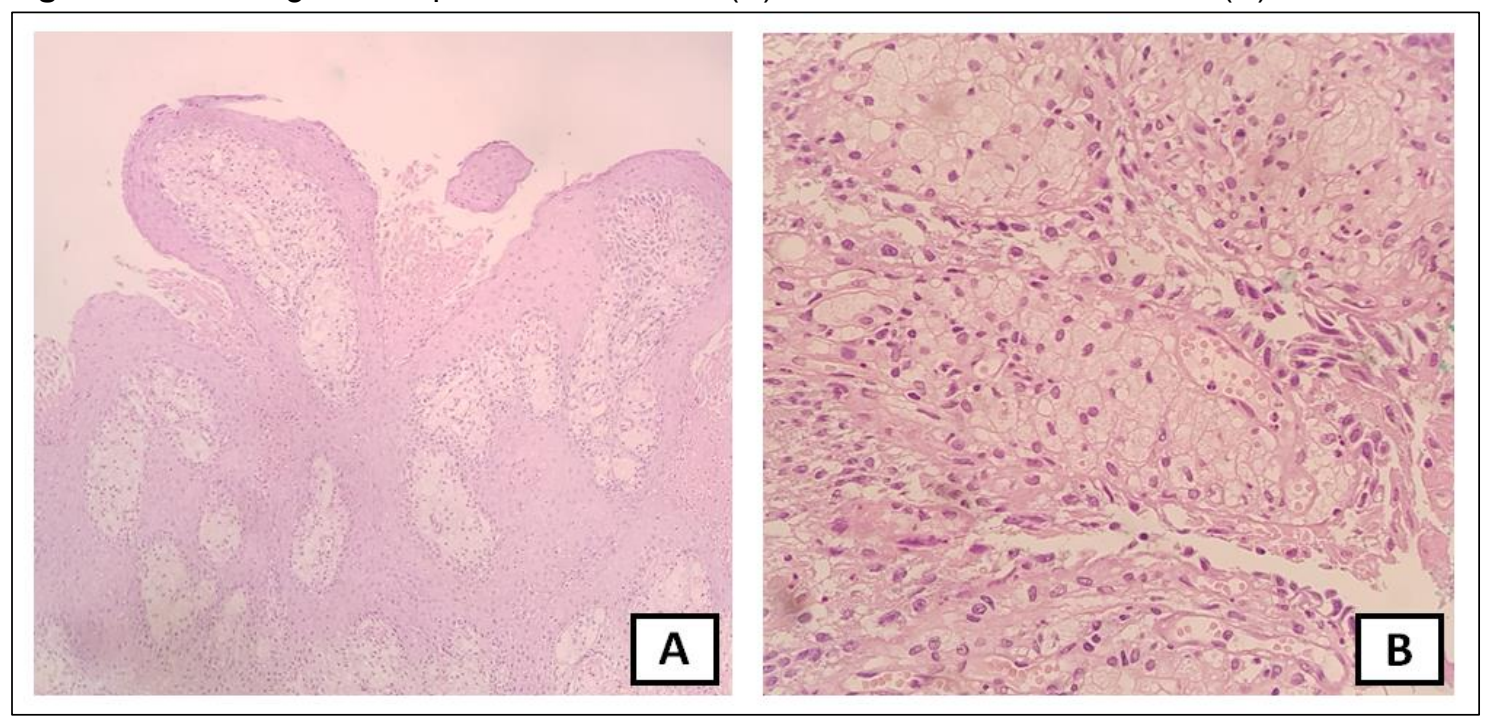

Fonte: Imagens cedidas pelo setor de patologia da instituição.

A paciente retornou ao ambulatório, assintomática, com o resultado da biópsia e cujas características histológicas foram compatíveis com dermatite liquenóide, e com o resultado da citologia oncótica, que demonstrou alterações celulares benignas, sugestivas de epitélio atrófico e reativo. Foi coletada uma nova biópsia da lesão vulvar, cujo laudo anatomo-patológico revelou achados histológicos sugestivos de dermatite/mucosite espongiótica. 
Após 7 dias, foi realizada a exérese da lesão vulvar, a qual foi enviada à análise anatomo-patológica. Retornou ao ambulatório para avaliação pós-cirúrgica (Figura 1B), assintomática, portando o laudo da análise histológica da lesão, que demonstrou se tratar de xantoma verruciforme, sem sinais de malignidade (Figura 2). Foi indicado seguimento ambulatorial à paciente.

\section{DISCUSSÃO}

O XV vulvar é considerado um pseudotumor relacionado ao crescimento celular ou tecidual, com características diversas em seu comportamento biológico que o distingui dos verdadeiros tumores da vulva. É uma lesão benigna, rara e comporta-se como uma lesão inflamatória e reativa. Apesar da sua etiopatogenia exata não estar ainda completamente esclarecida, um evento traumático parece ser a causa mais aceita como origem desta lesão. (FITE C, et al., et al., 2011; MEZQUITA, et al., 2018; ABREU L, et al., 2013).

O XV vulvar é considerado um pseudotumor relacionado ao crescimento celular ou tecidual, com características diversas em seu comportamento biológico que o distingui dos verdadeiros tumores da vulva. É uma lesão benigna, rara e comporta-se como uma lesão inflamatória e reativa. Apesar da sua etiopatogenia exata não estar ainda completamente esclarecida, um evento traumático parece ser a causa mais aceita como origem desta lesão. (FITE C, et al., et al., 2011; MEZQUITA G, et al., 2018; ABREU L, et al., 2013).

Em um relato de caso realizado no Japão, foi retratado o quadro de uma paciente de 50 anos submetida a uma cirurgia oncoginecológica, evoluindo com linfedema nas pernas e posteriormente estendido para a área vulvar, associado a celulite de repetição. Dois anos após este episódio, um nódulo assintomático, laranjaavermelhado e bem demarcado, com uma superfície verrucosa, desenvolveu-se na pele da vulva, sendo diagnosticado como XV por meio do estudo anatomopatológico. A pele da região vulvar havia sido afetada repetidamente por infecção e friç̧ão, o que poderia ter facilitado a degeneração dos queratinócitos e resultou na formação dessa patologia. A paciente analisada nesse trabalho, a princípio, não havia história evidente de trauma vulvar para despertar esse processo fisiopatológico. Portanto, sugere-se que a queixa de prurido vulvar apresentada no momento da consulta, favorece a teoria de que a etiologia da XV esteja associado a traumas de repetição (IJICHI A, et al., 2016).

O XV é uma desordem inflamatória que acomete predominantemente a cavidade oral. Histopatologicamente, essa lesão pode assemelhar-se a outros xantomas dérmicos, contudo, distinguindo-se destes por não estar associada a nenhuma alteração metabólica, como diabetes ou hiperlipemia. Em um estudo clínico feito na Faculdade de Medicina da Universidade do Porto, avaliou-se uma paciente do sexo feminino de 50 anos de idade com uma lesão traumática na mucosa jugal esquerda. $O$ exame histológico do tecido biopsiado revelou características compatíveis com XV. No presente estudo, a lesão encontrada na paciente teve características clínicas, epidemiológicas e histopatológicas semelhantes, tendo, portanto, o mesmo diagnóstico fechado de XV, no entanto em região vulvar, local fortuitamente descrito em literatura (ABREU L, et al., 2013).

Desde os primeiros relatos deste tumor, poucos casos foram descritos na região da vulva, sendo alguns desses associados a outra condição vulvar. Em um estudo realizado na França, teve-se 10 casos analisados, em que todos esses foram associados a uma condição vulvar, principalmente um líquen escleroso. Esse fato não coincidiu com o presente estudo, pois a paciente em questão teve o diagnóstico isolado de XV vulvar (FITE C, et al., 2011; MEZQUITA G, et al., 2018).

Apesar dos raros casos referidos na literatura, os XV vulvares já foram descritos em uma variedade de etnias, incluindo afro-americanas, chinesas, caucasianas, colombianas e japonesas. A localização exata da lesão foi relatada no clitóris, genitália externa, mucosa genital, dobra inguinal, grandes lábios, lábios menores e vulva não caso contrário especificado. A cor de a lesão era mais comumente amarelada laranja (STIFF KM e COHEN PR, 2017).

No que diz respeito a epidemiologia da patologia abordada, sabe-se que essas lesões afetam principalmente mulheres na pós-menopausa e geralmente se apresentam como lesão superficial única, espessa, irregular ou verrucosa e assintomática, exatamente o que foi encontrado na paciente analisada, 
tanto em relação ao quadro epidemiológico, quanto em relação ao quadro clinico apresentado. Entretanto, a clínica pode variar, sendo as lesões descritas como pápulas, placas ou nódulos, pedunculadas, medindo de 0,2 a 2 cm de diâmetro. Com relação à coloração, há uma variação, provavelmente, dependendo do grau de queratinização e do número de células xantomatosas presentes. Também podem ser múltiplas, bilaterais, inguinais e extensas (FITE C, et al., 2011; ARIAS VL, et al., 2010).

Existem casos associados ao carcinoma de células escamosas, provavelmente por coincidência, já que o $X V$ é considerado uma lesão benigna, não tumoral. A paciente em estudo possuía história prévia de carcinoma escamoso, entretanto, a literatura mostra que não se deve considerar o XV como lesão pré-maligna, de modo que o surgimento de ambas as lesões se trata apenas de mera casualidade (ARIAS VL, et al., 2010; MANNES KD, et al., 1999).

O diagnóstico pode ser feito erroneamente como verruga genital, carcinoma verrucoso ou carcinoma espinocelular (CEC), o que ocorreu a princípio com a paciente estudada, já que a primeira hipótese diagnóstica levantada sobre a lesão vulvar foi de carcinoma de vulva. Devido às características clínicas enganosas, o diagnóstico de XV vulvar é determinado principalmente pelo patologista, sendo as principais características histopatológicas a hiperplasia da epiderme, com extensa paraqueratose, exocitose de neutrófilos e aglutinação de histiócitos xantomatosos na derme papilar (FITE C, et al., 2011; MEZQUITA G, et al., 2018; CHUAN-HANG Y, et al., 2007).

\section{REFERÊNCIAS}

1. ABREU L, DIAS R. Xantoma Verruciforme: A propósito de um caso clínico. Rev Port Estomatol Med Dent Cir Maxilofac. 2013; 54(S1):e1-e59.

2. AGARWAL AN, et al. A giant verruciform xanthoma. Journal of Cutaneous Pathology, 2002; 29: 119-124.

3. ARIAS VL, RODRÍGUEZ G. Xantoma verruciforme: características histopatológicas y patogénesis, análisis de casos de vulva y región perianal. Rev Asoc Colomb Dermatol. 2010;18: 160-65.

4. BEUTLER BD, COHEN PR. Verruciform Genital-Associated (Vegas) Xanthoma: report of a patient with verruciform xanthoma of the scrotum and literature review. Dermatol Online J, 2015; 15;21(8).

5. CHUAN-HANG Y, et al. Oral Verruciform Xanthoma: A Clinicopathologic Study of 15 Cases. J Formos Med Assoc, 2007; vol 106, n2.

6. FITE C, et al. Vulvar Verruciform Xanthoma: Ten Cases Associated With Lichen Sclerosus, Lichen Planus, or Other Conditions. Arch Dermatol, 2011; 147(9):1087-1092.

7. IJICHI A, et at. Vulvar verruciform xanthoma developing in acquired lymphangioma circumscriptum. J Dermatol, 2017; 44(5):604-605.

8. MANNES KD, et al. Verruciform xanthoma associated with squamous cell carcinoma. Am J Dermopathol, 1999; 21(1):66-9.

9. MEZQUITA G, et al. Xantoma verruciforme vulvar: una localización poco común. Clínica e Investigación en Ginecología y Obstetricia, 2018; 45(3): 131-133.

10. MONTEIRO MCL et al., 2016. Verruciform xanthoma: case report. Rev Gaúcha de Odontologia, 2016; v64, n.1, p.7982.

11. ROSA EA, AMORIM RFB. A rare case of giant verruciform xanthoma in the palate. Rev Gaúcha Odontol., 2014; v.62, n.1, p. 77-81.

12. STIFF KM, COHEN PR. Vegas (Verruciform Genital-Associated) Xanthoma: A Comprehensive Literature Review; Dermatol Ther (Heidelb) (2017) 7:65-79. 